\title{
DEVELOPMENT OF ORGANIZATIONAL AND TECHNICAL METHODS FOR PREDICTING EMERGENCY SITUATIONS AND POSSIBLE LOSSES AS THEIR RESULTS
}

\author{
Hryhorii Ivanets \\ Department of Fire Tactics and Rescue Operations \\ National University of Civil Defence of Ukraine \\ 94 Chernyshevska str., Kharkiv, Ukraine, 61023 \\ Stanislav Horielyshev \\ Scientific and Research Center of Service and Military Activities \\ of the National Guard of Ukraine ${ }^{l}$ \\ Martin Sagradian \\ Department of Mathematics and Statistics \\ Macquarie University \\ 16 University ave., Sydney, NSW Australia, 2109 \\ Mykhailo Ivanets \\ Scientific and Research Center of the Air Force ${ }^{2}$ \\ Igor Boikov $₫$ \\ Department of Armoured Vehicles ${ }^{1}$ \\ biv543@ukr.net \\ Dmitro Baulin \\ Scientific and Research Center of Service and Military Activities \\ of the National Guard of Ukraine \\ Yurij Kozlov \\ Department of Metrology and Technical Expertise \\ Kharkiv National University of Radio Electronics \\ 14 Nauki ave., Kharkiv, Ukraine, 61166 \\ Aleksandr Nakonechnyi \\ Department of Armament of Air Defense of Ground Forces ${ }^{2}$ \\ Lyudmila Safoshkina \\ Scientific and Research Center of Service and Military Activities \\ of the National Guard of Ukraine ${ }^{l}$ \\ ${ }^{1}$ National Academy of the National Guard of Ukraine \\ 3 Zakhysnykiv Ukrainy sq., Kharkiv, Ukraine, 61001 \\ ${ }^{2}$ Ivan Kozhedub Kharkiv National Air Force University \\ 77/79 Symska str., Kharkiv, Ukraine, 61023
}

$\triangle$ Corresponding author

Abstract

Emergency prevention is based on analysis, forecasting and early response to emergencies. A systematic approach to solving the problem of preventing emergencies envisages forecasting emergencies by type, level and possible losses caused as a their results both in the state as a whole and in its regions. To implement a systematic approach based on a formalized mathematical model, an organizational and technical method has been developed for predicting emergencies and possible losses caused as their results. 
The method is a combination of a variable order polynomial regression method, a weighted least squares method, and a probabilistic statistical method. This allows to compensate for the shortcomings of some at the expense of others, which will lead to an increase in forecasting accuracy.

A control algorithm has been developed for the implementation of an organizational and technical method for predicting emergency situations and possible losses caused as their results. Its use involves the implementation of a number of interrelated procedures. At the first stage, the collection, processing and analysis of information on emergency situations in the country for a certain period of monitoring is carried out. This is the basis for predicting the processes of emergencies in general, in nature, level and types, as well as losses due to them both in the state and its regions. The information received is taken into account when forming a decision on the actions of civil protection units in order to adequately respond to emergency situations and eliminate their consequences. Based on the analysis of the effectiveness of the actions of the response units, the decisions on the elimination of emergency situations are adjusted.

The developed method makes it possible to reasonably approach the planning and implementation of organizational and technical measures to prevent emergency situations, taking into account the potential threats to the territories and population of the country's regions.

Keywords: formalized model, organizational and technical method, control algorithm, emergency, losses.

DOI: $10.21303 / 2461-4262.2021 .002007$

\section{Introduction}

In the last decade, a stable trend of climate change has been observed all over the world, an increase in the level of seismic activity of the earth's crust, an increase in the size and power of technical systems, and a progressive human intervention in nature [1]. All this significantly increases the risks of man-made accidents and natural disasters, which leads to an increase in the number and scale of emergency situations of various natures.

The consequences of emergencies negatively affect the environment [2], the economies of countries [3], are accompanied not only by material, but also human losses, the spread of epidemics and pandemics.

The experience of the developed countries of the world shows that the costs of measures related to the prevention of emergency situations are much less than the costs of restoring the losses caused by them and the damage to the environment.

Emergency prevention is a set of measures aimed at regulating natural and man-made safety, assessing risk levels and responding in advance to them in order to prevent emergencies or mitigate possible consequences [4].

An important aspect of this activity is the early forecasting of the possibility of occurrence and economic consequences of emergencies of a technogenic, natural and social nature.

Therefore, the development of an organizational and technical method for predicting emergencies and possible losses caused as their results both in the state and its regions is an urgent scientific and practical problem in the field of civil protection. Solving this problem will increase the efficiency of planning and carrying out a set of measures to prevent emergencies or minimize possible consequences.

The effectiveness of planning and implementing measures to prevent emergencies is determined by the quality of forecasting emergencies threats and possible consequences as their results. Disaster prevention is based on analysis, early detection, forecasting and early response to emergencies. A systematic approach to solving the problem of forecasting emergency situations and possible losses caused as their results provides for forecasting emergency situations in the whole country and its regions; forecasting natural emergencies in general, by type and level; forecasting emergency situations of a technogenic nature; forecasting emergency situations of a social nature by types, levels; forecasting possible losses as a result of emergency situations.

Information containing information on the predicted number of emergencies, possible damage and consequences as their results is important for the development of measures to prevent and respond to emergencies. Emergency forecasting methods depend on the available statistical information about emergency situations and the dynamics of their development after 
some previous monitoring period, as well as the causes and factors that cause emergencies of a different nature.

Forecasting emergencies of various nature and consequences as their results is carried out on the basis of the analysis of statistical information about emergencies in the state after some previous monitoring period.

When predicting emergency situations $[5,6]$, consider:

- statistical information on man-made and natural sources of emergency situations;

- possible options for the emergence and development of emergencies;

- results of extrapolation of the identified trends;

- expert assessments.

Forecasting emergencies of various natures has its own levels of complexity, for example, natural emergencies carry a large component of uncertainty, in contrast to man-made emergencies, which mainly depend on the state of technology and the human factor and are subject to formalized calculations.

The authors of works $[7,8]$ considered and analyzed the probabilistic-statistical, probabilistic-deterministic, deterministic-probabilistic methods of forecasting emergency situations of a technogenic and natural character.

The main disadvantage of the probabilistic approach is the complexity of developing models of emergency processes, which significantly complicates the analysis of the development of these processes in dynamics. To overcome these inconveniences, linear, nonlinear, stepwise, ordinal regressions are used [9]. The advantages of these models include simplicity, flexibility, and unambiguity of their analysis and design.

The disadvantages of linear regression models are low adaptability and the lack of the ability to model nonlinear processes. To estimate the parameters of linear regression models, the ordinary least squares method (OLS) is used. One of the conditions for using OLS to obtain unbiased independent effective estimates of the parameters of the regression model is the constancy of the variance of the residuals for each observation or groups of observations (homoscedantity of the residuals). Since the models of the processes of emergence of natural and man-made emergencies, as a rule, have a non-linear character, this condition is not met. This means that the estimates of the regression parameters obtained using OLS will not have a minimum variance, which worsens the forecast accuracy. One way to solve this problem is to use weighted OLS to estimate the parameters of the regression model.

The main disadvantage of nonlinear regression models is the complexity of determining the type of functional dependence, as well as the difficulty of determining the parameters of the model [10].

To estimate the parameters of linear regression models [5], the ordinary least squares method (OLS) is used. One of the conditions for using OLS to obtain unbiased independent effective estimates of the parameters of the regression model is the constancy of the variance of the residuals for each observation or groups of observations (homoscedasticity of the residuals). Since the models of the processes of emergence of technogenic emergencies, as a rule, are nonlinear, this condition is not met. This means that the estimates of the regression parameters obtained using OLS will not have a minimum variance, which worsens the forecast accuracy. One way to solve this problem is to use weighted OLS to estimate the parameters of the regression model.

A large number of technogenic emergencies are caused by violations associated with equipment failure (due to its lack of reliability, suitability, functional qualities during operation, physical wear and tear). The root causes of equipment malfunctions are lack or inadequate monitoring of equipment performance or lack of procedures. One of the main ways to prevent technogenic emergencies [5] is to ensure reliable control over the condition and operation of equipment at industrial and other enterprises, and effective preventive measures.

For modeling nonlinear processes, such as the processes of occurrence of technogenic and natural emergencies, the authors of [11] propose to use neural network models. The main advantage of neural network models is nonlinearity, that is, the ability to establish nonlinear relationships between the future and actual values of processes. The disadvantages of such models are the lack of 
transparency in modeling, the complexity of the choice of architecture and the learning algorithm of the neural network.

The authors of [12] have developed methods for predicting the risks associated with emergencies as a result of forest fires, and losses from emergencies. A significant drawback of this work is the lack of a mathematical apparatus that would describe the relationship of physical processes at different stages of the emergence and course of emergencies of this type. An effective method of preventing emergencies [13] is to determine the source of the fire from artificial earth satellites. The availability of satellite data of high spatial resolution based on a geographic information system (GIS) allows solving the problems of early detection of forest fires and determining their spatial coordinates in real time, predicting their consequences and developing a set of measures to prevent their development. The main disadvantages of such systems are the low accuracy of detecting fire foci and the need to develop a general mathematical model for preventing such emergencies.

In [6], a combined method for predicting the process of emergence of natural emergencies is proposed, which allows taking into account the tendencies of periodic changes in this process. However, the frequency of changes in the processes of emergencies is characteristic only for natural emergencies and is not typical for emergencies of a technogenic or social nature.

Methods of expert assessments and sociological research are used to predict emergencies of a social nature; statistical and probabilistic methods that use data after a certain previous monitoring period have been studied to a lesser extent [5]. The methods of expert assessments are based on: obtaining the necessary information from qualified specialists of various profiles; scientific generalization of individual opinions of experts to develop an objective judgment on this issue.

Prediction of possible incurred losses as a result of an accident is possible only on the basis of an analysis of factual information about emergencies in the state for a certain period of monitoring. Factographic forecasting methods [10] are based on emergency monitoring data. Factual forecasting methods include extrapolation and interpolation methods, methods of extrapolation by envelope curves, regression and correlation, factor models, expert models of logical modeling, construction of development scenarios [5, 14]. In most cases, regression analysis methods are used to solve this problem; statistically - probabilistic methods that use factual information for a certain monitoring period have been studied to a lesser extent.

Thus, the analysis of literary sources shows that the known methods are mainly aimed at predicting certain types of emergencies of a technogenic and natural nature. They are not of a systemic nature and do not allow the forecast of emergencies as a whole, by type and level, of possible losses incurred both in the state and its regions.

This indicates the need to develop an organizational and technical method (OTM) for forecasting emergencies and possible losses caused as their results both in the state and its regions on the basis of a systematic approach to solving this problem.

The aim of research is to develop OTM for forecasting emergencies and the damage caused as their results.

To achieve this aim, it is necessary to solve the following objectives:

1. Develop, on the basis of a formalized mathematical model, OTM for forecasting emergency situations and possible losses caused as their results.

2. Develop a control algorithm for the implementation of OTM for forecasting emergency situations and possible losses caused as their results.

3. Check the effectiveness of the use of OTM for forecasting emergencies and possible losses caused as their results.

\section{Materials and methods}

2. 1. Development of an organizational and technical method for predicting emergency situations and damage caused as their results

The method is based on a formalized mathematical model for predicting emergency situations and possible losses caused as their results, which has the form: 


$$
\begin{aligned}
& n_{E}(t)=U_{1}\left\{r_{0}, r_{1}, r_{2}, \ldots, t\right\} ; \\
& n_{E}^{i}(t)=U_{2}\left\{n_{E}(t), P_{E}^{i}\right\} ; \\
& n_{T C}(t)=F_{1}\left\{n_{E}(t), P_{T C}\right\} \text {; } \\
& n_{N C}(t)=F_{2}\left\{n_{E}(t), P_{N C}\right\} ; \\
& n_{S C}(t)=F_{3}\left\{n_{E}(t), P_{S C}\right\} ; \\
& l_{i}(t)=\psi_{1}\left\{n_{T C}(t), P_{T C_{i}}\right\} ; \\
& v_{i}(t)=\psi_{2}\left\{n_{N C}(t), P_{N C_{i}}\right\} ; \\
& r_{i}(t)=\psi_{3}\left\{n_{S C}(t), P_{S C_{i}}\right\} \text {; } \\
& n_{T C}^{i}(t)=S_{1}\left\{n_{T C}(t), P_{T C}^{i}\right\} ; \\
& n_{N C}^{i}(t)=S_{2}\left\{n_{N C}(t), P_{N C}^{i}\right\} \text {; } \\
& n_{S C}^{i}(t)=S_{3}\left\{n_{S C}(t), P_{S C}^{i}\right\} \text {; } \\
& n_{D P}(t)=Q_{1}\left\{n_{E}(t), P_{D P}\right\} ; \\
& n_{P P}(t)=Q_{2}\left\{n_{E}(t), P_{P P}\right\} \text {; } \\
& n_{M P}(t)=Q_{3}\left\{n_{E}(t), P_{M P}\right\} \text {; } \\
& n_{O P}(t)=Q_{4}\left\{n_{E}(t), P_{O P}\right\} \text {; } \\
& n_{D P}^{i}(t)=\Phi_{1}\left\{n_{D P}(t), P_{D P}^{i}\right\} \text {; } \\
& n_{P P}^{i}(t)=\Phi_{2}\left\{n_{P P}(t), P_{P P}^{i}\right\} \text {; } \\
& n_{M P}^{i}(t)=\Phi_{3}\left\{n_{M P}(t), P_{M P}^{i}\right\} \text {; } \\
& n_{O P}^{i}(t)=\Phi_{4}\left\{n_{O P}(t), P_{O P}^{i}\right\} \text {; } \\
& L(t)=\Theta\left\{n_{D P}(t), n_{P P}(t), n_{M P}(t), n_{O P}(t)\right\} ;
\end{aligned}
$$

where $n_{E}(t)$ - the number of emergency situations in the state; $\left(r_{0}, r_{1}, r_{2}, \ldots, r_{k}\right)$ - function parameters; $n_{E}^{i}(t)$ - the number of emergency situations in the $i$-th region; $P_{E}^{i}-$ likelihood of an emergency in the $i$-th region in the event of an emergency in the state; $n_{T C}(t), n_{N C}(t), n_{S C}(t)$ - the number of emergency situations in accordance with a technogenic, natural and social nature; $P_{T C}, P_{N C}, P_{S C}$ - probability of emergencies in accordance with the technogenic, natural and social character in the state; $l_{i}(t), v_{i}(t), r_{i}(t)$ - the number of emergency situations by type in accordance with the technogenic, natural and social character in the state; $P_{T C i}, P_{N C i}, P_{S C i}-$ the likelihood of emergencies of a technogenic, natural and social nature of the $i$-th type in the state; $n_{T C}^{i}(t), n_{N C}^{i}(t)$, $n_{S C}^{i}(t)$ - the number of emergency situations in accordance with the technogenic, natural and social character in the $i$-th region; $P_{T C}^{i}, P_{N C}^{i}, P_{S C}^{i}$ - likelihood of an emergency in accordance with a technogenic, natural and social nature in the $i$-th region in the event of an emergency in the state; $n_{D P}(t), n_{P P}(t), n_{M P}(t), n_{O P}(t)$ - the number of emergency situations, respectively, at the state, regional, local and facility levels; $P_{D P}, P_{P P}, P_{M P}, P_{O P}$ - probability of emergencies, respectively, at the state, regional, local and facility levels in the state; $n_{D P}^{i}(t), n_{P P}^{i}(t), n_{M P}^{i}(t), n_{O P}^{i}(t)$ - the number of emergency situations, respectively, of the state, regional, local and facility levels in the $i$-th region in the event of an emergency in the state; $P_{D P}^{i}, P_{P P}^{i}, P_{M P}^{i}, P_{O P}^{i}$ - probability of emergencies, respectively, of the state, regional, local and facility levels in the $i$-th region in the event of an emergency in the state; $L(t)$ - losses due to the emergencies in the state.

Thus, the formalized mathematical model for forecasting emergency situations and possible losses as their results is a system of formalized analytical dependencies that describe the processes of emergencies both in the state and in its regions.

In accordance with the model (1), OTM is proposed for forecasting emergency situations and losses due to them. For this, models have been developed for forecasting emergency situations in general, by type, by levels and losses due to them both in the state and its regions. The model for forecasting the total number of emergencies in the state is a power polynomial of the form: 


$$
n_{E}^{p r}=a_{0}+a_{1} t_{p r}+a_{2} t_{p r}^{2}+a_{3} t_{p r}^{3}+\ldots+a_{k} t_{p r}^{k}
$$

where $n_{E}^{p r}=n_{E}\left(t_{p r}\right)$ - predicted value of the number of emergency situations in the state at the time of the forecast $t=t_{p r} ;\left(a_{0}, a_{1}, a_{2}, \ldots, a_{k}\right)$ - the coefficients of the polynomial.

The polynomial coefficients are calculated based on the weighted least squares method [15].

The predicted number of emergencies in the $i$-th region of the state in accordance with the model (1) is calculated based on the predicted number of emergencies in the country $n_{E}^{p r}$ as a whole and the probability of emergencies in the region of the state $P_{E}^{i}$ as follows:

$$
n_{p r E}^{i}=n_{E}^{p r} \cdot P_{E}^{i}
$$

where $n_{p r E}^{i}=n_{E_{i}}\left(t_{p r}\right)$ - predicted number of emergencies in the $i$-th region of the state at the time of the forecast $t=t_{p r}$.

In this case, the following condition must be met:

$$
\sum P_{E}^{i}=1
$$

The predicted number of emergencies in the state by the nature of origin and levels (1) is calculated on the basis of the predicted total number of emergency situations in the state $n_{E}^{p r}$ and the probabilities of emergencies $P_{T C}, P_{N C}, P_{S C}, P_{D P}, P_{P P}, P_{M P}, P_{O P}$ of the corresponding nature and level [6]:

$$
\begin{gathered}
n_{p r T C}=n_{E}^{p r} \cdot P_{T C} ; n_{p r N C}=n_{E}^{p r} \cdot P_{N C} ; n_{p r S C}=n_{E}^{p r} \cdot P_{S C}, \\
n_{p r D P}=n_{E}^{p r} \cdot P_{D P} ; n_{p r P P}=n_{E}^{p f} \cdot P_{P P} ; n_{p r M P}=n_{E}^{p r} \cdot P_{M P} ; n_{p r O P}=n_{E}^{p r} \cdot P_{O P},
\end{gathered}
$$

where $n_{p r T C}=n_{T C}\left(t_{p r}\right), n_{p r N C}=n_{N C}\left(t_{p r}\right), n_{r S C}=n_{S C}\left(t_{p r}\right)$ - predicted number of emergency situations in accordance with a technogenic, natural and social nature in the state for the forecast period $n_{E D P}=n_{D P}\left(t_{p r}\right), n_{p r P P}=n_{P P}\left(t_{p r}\right), n_{p r M P}=n_{M P}\left(t_{p r}\right), n_{p r O P}=n_{O P}\left(t_{p r}\right)$ - predicted number of emergency situations, respectively, at the state, regional, local and facility levels in the state at the time of forecast $t=t_{p r}$.

In this case, the following conditions must be met:

$$
P_{T C}+P_{N C}+P_{S C}=1 ; P_{D P}+P_{P P}+P_{M P}+P_{O P}=1
$$

In accordance with the model (1), the predicted number of emergencies of the corresponding nature and level in the regions of the state is equal to:

$$
\begin{gathered}
n_{p r T C}^{i}=P_{T C}^{i} \cdot n_{p r T C} ; n_{p r N C}^{i}=P_{N C}^{i} \cdot n_{p r N C} ; n_{p r S C}^{i}=P_{S C}^{i} \cdot n_{p r S C}, \\
n_{p r D P}^{i}=P_{D P}^{i} \cdot n_{p r D P} ; n_{p r P P}^{i}=P_{P P}^{i} \cdot n_{p r P P} ; n_{p r M P}^{i}=P_{M P}^{i} \cdot n_{p r M P} ; n_{p r O P}^{i}=P_{O P}^{i} \cdot n_{p r O P},
\end{gathered}
$$

where $n_{p r T C}^{i}=n_{T C_{i}}\left(t_{p r}\right), n_{p r N C}^{i}=n_{N C_{i}}\left(t_{p r}\right), n_{p r S C}^{i}=n_{S C_{i}}\left(t_{p r}\right)$ - predicted number of emergencies in accordance with the technogenic, natural and social nature in the $i$-th region of the state for the forecast period; $n_{p r D P}^{i}=n_{D P}^{i}\left(t_{p r}\right), n_{p r P P}^{i}=n_{P P}^{i}\left(t_{p r}\right), n_{p r M P}^{i}=n_{M P}^{i}\left(t_{p r}\right), n_{p r O P}^{i}=n_{O P}^{i}\left(t_{p r}\right)$-predicted number of emergency situations, respectively, at the state, regional, local and facility levels in the regions of Ukraine for the forecast period.

In this case, the following condition must be met:

$$
\sum P_{T C}^{i}=1 ; \quad \sum P_{N C}^{i}=1 ; \quad \sum P_{S C}^{i}=1
$$

The predicted number of emergencies by type in accordance with the technogenic, natural and social nature in the state is calculated based on the forecast of the total number of technogenic, natural and social emergencies in the country: 


$$
l_{i}\left(t_{p r}\right)=n_{p r T C} \cdot P_{T C_{i}} ; v_{i}\left(t_{p r}\right)=n_{p r N C} \cdot P_{N C_{i}} ; r_{i}\left(t_{p r}\right)=n_{p r S C} \cdot P_{S C_{i}},
$$

the necessary conditions:

$$
\sum P_{T C_{i}}=1 ; \sum P_{N C_{i}}=1 ; \sum P_{S C_{i}}=1
$$

Forecast data on the number of natural, technogenic and social emergencies in accordance with the types and levels are the basis for assessing possible losses as their results. The total forecasted losses as result of an emergency in the state is the amount of damage caused as a result of an emergency of a man-made, natural and social nature:

$$
L\left(t_{p r p}\right)=L_{T C}\left(t_{p r}\right)+L_{N C}\left(t_{p r}\right)+L_{S C}\left(t_{p r}\right)
$$

where $L\left(t_{p r}\right)$ - total predicted losses as a result of emergency situations; $L_{T C}\left(t_{p r}\right)-$ losses due to emergencies of a technogenic nature; $L_{N C}\left(t_{p r}\right)$ - losses due to emergencies of a natural nature; $L_{S C}\left(t_{p r}\right)$ - losses due to emergencies of a social nature.

Forecasting of losses due to emergencies of a technogenic nature of $L_{T C}\left(t_{p r}\right)$ is carried out in accordance with the regression-probabilistic forecasting method. It takes into account the average losses and their standard deviations from real values based on the statistical data on emergencies for a certain monitoring period.

Estimates of the predicted values of losses will be in the range:

$$
L_{p r T C}^{a v}-\sigma<L_{T C}\left(t_{p r}\right)<L_{p r T C}^{a v}+\sigma,
$$

where $L_{p r T C}^{a v}$ - estimate of the predicted average damage caused as a result of a technogenic emergency; $L_{T C}\left(t_{p r}\right)$ - estimate of the predicted damage caused by emergencies of a technogenic nature; $\sigma$-average deviation of the estimated estimates of the damage caused as a result of a technogenic emergency.

Prediction of possible losses as a result of natural emergencies is based on the fact that the total amount of damage from them is calculated as the sum of losses due to emergencies of various types:

$$
L_{N C}\left(t_{p r}\right)=\sum_{j=1}^{n} L_{j}\left(t_{p r}\right)
$$

where $L_{N C}\left(t_{p r}\right)$ - total amount of forecasted losses due to emergencies of a natural nature; $L_{j}\left(t_{p r}\right)$ - losses due to natural emergencies of the $j$-th type.

Forecasted losses as a result of natural emergencies of the $j$-th type can be estimated taking into account their number by levels and the share in incurred losses per one emergency. So, for example, the predicted losses as a result of the emergencies of a hydrometeorological nature can be estimated in accordance with the following expression:

$$
L_{j}\left(t_{p r}\right)=v_{j D P}\left(t_{p r}\right) \cdot \Pi_{j D P}+v_{j P P}\left(t_{p r}\right) \cdot \Pi_{j P P}+v_{j M P}\left(t_{p r}\right) \cdot \Pi_{j M P}++v_{j O P}\left(t_{p r}\right) \cdot \Pi_{j O P},
$$

where $\Pi_{j D P}, \Pi_{j P P}, \Pi_{j O P}, \Pi_{j M P}$ - the share in the inflicted losses of the $j$-th type of the national system, respectively, of the state, regional, local and facility levels; $v_{j D P}\left(t_{p r}\right), v_{j P P}\left(t_{p r}\right), v_{j M P}\left(t_{p r}\right)$, $v_{j O P}\left(t_{p r}\right)$ - predicted number of emergency situations of the $j$-th type, respectively, of the state, regional, local and facility levels.

Forecasting of losses due to a social accident of the $L_{I C}\left(t_{p r}\right)$ is carried out on the basis of the average losses per one accident and the forecasted number of emergency situations.

Thus, the proposed OTM for forecasting emergencies and possible losses caused as their results.

The method is based on a formalized mathematical model, which includes:

- wmergency forecasting models for the whole country and its regions;

- forecasting models of natural emergencies in general, by types and levels in the state and its regions; 
- forecasting models of technogenic emergencies in general, by types and levels in the state and its regions;

- forecasting models for emergencies of a social nature in general, by type and level in the state and its regions;

- models of forecasting losses due to the emergencies in the state.

\section{2. Development of a control algorithm for an organizational and technical method} for predicting emergencies and damage caused as their results

The control algorithm that implements OTM for predicting emergency situations and damage caused as their results, shown in Fig. 1. The algorithm consists of 9 blocks located at 7 hierarchical levels.

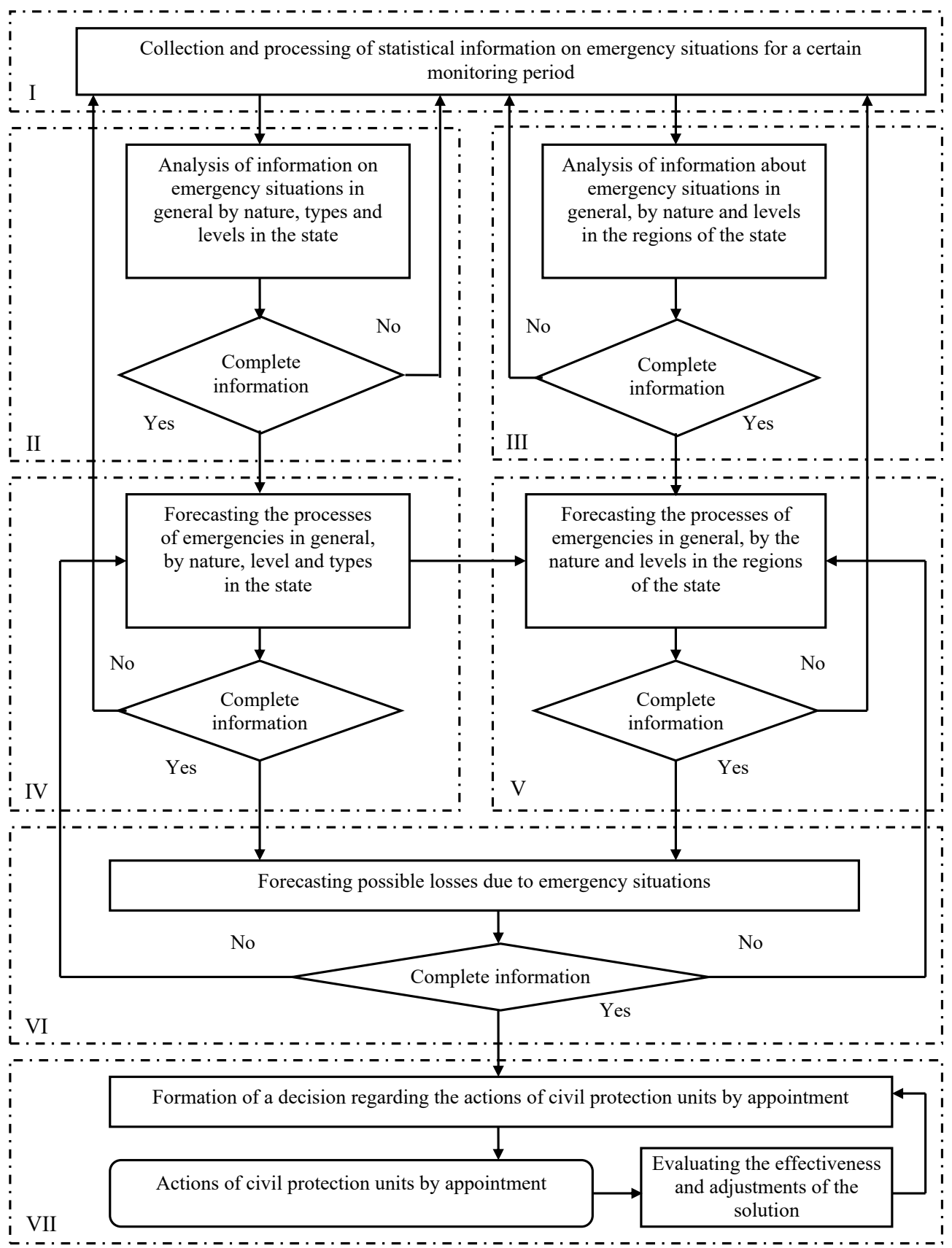

Fig. 1. The control algorithm of the organizational and technical method for predicting emergencies and damage caused as their results 
The first level is a block for collecting and processing statistical information about emergencies for a certain monitoring period. Collection of information about sources, risks and consequences of emergencies is aimed at obtaining statistical information about emergencies both in the state as a whole and in its regions. Systematization of information provides for such processing and reduction of information to a form that allows for its analysis and development of management decisions. The second level includes a block for analyzing information about emergencies as a whole, by nature, types and levels in the state. At the third level, there is a block for analyzing information about emergency situations in general, by nature and levels in the regions of the state. At the fourth level, there is a block for forecasting the processes of emergencies in general, by nature, level and types in the state. At the fifth level there is a block for forecasting processes.

At the sixth level, there is a block for predicting possible losses caused as a result of emergency situations. The seventh level is a block for forming a decision regarding the actions of civil protection units (CP) for the intended purpose and a block for evaluating the effectiveness and correcting decisions based on an analysis of the actions of CP units.

Thus, the OTM control algorithm for forecasting emergency situations and losses due to them implements the developed mathematical model and consists of 9 blocks, which are located at 7 hierarchical levels and are connected by direct and feedback links.

\section{Results and discussion}

Let's check the effectiveness of the developed method on the basis of emergency monitoring statistics for a certain period of observation. It should be noted, however, that statistical data must be complete, objective and correct. Otherwise, the results obtained may have significant errors, or may not correspond to reality at all.

The features of the use of OTM for forecasting emergencies and the damage caused as their results in different countries will be determined by the following factors:

- availability and reliability of emergency statistics;

- regional structure of the state;

- specifics of the classification of emergency situations by type and level.

Based on the statistical data on emergencies [16, 17], studies of the effectiveness of the use of OTM were carried out on the example of Ukraine, based on the following reasons:

- unlike other countries, for Ukraine, correct statistical data on emergencies in general, by type, level and nature of origin, are fully generalized;

- for emergencies, there are known signs of their classification by types and levels.

However, only statistical data for 2013-2018 were taken into account, since the data for 2019 and 2020 are not entirely correct and do not correspond to reality throughout Ukraine. This is due to the lack of data on emergencies in some territories of the state temporarily controlled by Ukraine. Therefore, forecasting emergency situations for 2019-2020 due to the lack of data on emergency situations in such parts of Ukraine as Autonomous Republic of Crimea, Donetsk, Luhansk regions will have significant errors.

As an efficiency criterion, let's choose the module of the relative forecast error, which is calculated on the basis of previous statistical data as follows:

$$
|\Delta|=\frac{\sum_{i=1}^{n}\left|\Delta_{i}\right|}{n},
$$

where $|\Delta|$ - module of the average relative forecast error; $\left|\Delta_{i}\right|$ - module of the relative error of the $i$-th step of the forecast; $n$ - amount of statistical data.

The forecast of the number of emergencies in general, by type and level both in the state and its regions, in this study is assessed as an optimistic option $n_{E}^{p r_{o}}=n_{E}^{p r}(1-|\Delta|)$, and a pessimistic one $n_{E}^{p r_{n}}=n_{E}^{p r}(1+|\Delta|)$.

The results of studies using OTM for predicting emergencies and damage caused as their results are given in Table $\mathbf{1}$. 
Table 1

Comparison of forecast and actual values for the period 2013-2018

\begin{tabular}{|c|c|c|c|c|c|c|c|}
\hline \multirow{2}{*}{ Parameter } & & \multicolumn{6}{|c|}{ Year } \\
\hline & & \multirow{2}{*}{$\begin{array}{c}2013 \\
75\end{array}$} & \multirow{2}{*}{$\begin{array}{c}2014 \\
74\end{array}$} & \multirow{2}{*}{$\begin{array}{c}2015 \\
63\end{array}$} & \multirow{2}{*}{$\begin{array}{c}2016 \\
56\end{array}$} & \multirow{2}{*}{$\begin{array}{c}\mathbf{2 0 1 7} \\
50\end{array}$} & \multirow{2}{*}{$\begin{array}{c}\mathbf{2 0 1 8} \\
48\end{array}$} \\
\hline Number of technogenic emergencies & Actual quantity & & & & & & \\
\hline & Optimistic forecast & 74 & 67 & 59 & 54 & 49 & 46 \\
\hline & Pessimistic forecast & 86 & 79 & 67 & 62 & 54 & 50 \\
\hline \multirow[t]{3}{*}{ Number of natural emergencies } & Actual quantity & 56 & 59 & 77 & 89 & 107 & 77 \\
\hline & Optimistic forecast & 51 & 48 & 62 & 88 & 97 & 76 \\
\hline & Pessimistic forecast & 58 & 59 & 78 & 97 & 108 & 81 \\
\hline \multirow[t]{3}{*}{ Number of social emergencies } & Actual quantity & 12 & 10 & 8 & 4 & 9 & 3 \\
\hline & Optimistic forecast & 11 & 9 & 7 & 4 & 8 & 3 \\
\hline & Pessimistic forecast & 15 & 13 & 9 & 6 & 11 & 5 \\
\hline \multirow[t]{3}{*}{ Number of emergency situations at the state level } & Actual quantity & 1 & 5 & 2 & 1 & 2 & 2 \\
\hline & Optimistic forecast & 1 & 4 & 1 & 1 & 1 & 1 \\
\hline & Pessimistic forecast & 2 & 5 & 2 & 2 & 2 & 2 \\
\hline \multirow[t]{3}{*}{ Number of emergency situations at the regional level } & Actual quantity & 11 & 9 & 9 & 9 & 8 & 6 \\
\hline & Optimistic forecast & 10 & 8 & 8 & 8 & 7 & 5 \\
\hline & Pessimistic forecast & 12 & 10 & 9 & 9 & 9 & 7 \\
\hline \multirow[t]{3}{*}{ Number of emergency situations at the local level } & Actual quantity & 58 & 59 & 62 & 64 & 70 & 64 \\
\hline & Optimistic forecast & 55 & 52 & 54 & 56 & 63 & 63 \\
\hline & Pessimistic forecast & 64 & 62 & 64 & 67 & 72 & 65 \\
\hline \multirow[t]{3}{*}{ Number of emergency situations at the facility level } & Actual quantity & 73 & 70 & 75 & 75 & 86 & 56 \\
\hline & Optimistic forecast & 70 & 62 & 65 & 66 & 79 & 55 \\
\hline & Pessimistic forecast & 81 & 74 & 77 & 78 & 89 & 58 \\
\hline \multirow[t]{3}{*}{ Losses due to emergencies (million EUR) } & Actual quantity & 12.01 & 6.02 & 16.14 & 8.04 & 27.18 & 15.45 \\
\hline & Optimistic forecast & 11.82 & 4.55 & 13.64 & 6.67 & 24.25 & 13.7 \\
\hline & Pessimistic forecast & 13.64 & 6.36 & 16.24 & 8.18 & 27.27 & 15.69 \\
\hline
\end{tabular}

Using expressions (9)-(12), predictive (optimistic, pessimistic) values of losses due to emergency situations are calculated. Analyzing the statistical data [16, 17] and expression (12), it is possible to conclude that the main contribution to the amount of losses from emergencies is made by the emergencies of the state level, and then the regional one.

From the data obtained (Table 1), it can be seen that when predicting, for example, the number of technogenic emergencies for 2018, let's obtain a range of possible values from 46 to 50 . Moreover, the actual value of the number of emergencies is 48 . Based on the forecast of the number of emergencies, an assessment of losses due to these emergency situations was carried out. The calculation of losses due to the emergencies was carried out in the national currency of Ukraine (UAH), however, for clarity, in Table 1 the received data are recalculated at the current exchange rate and reflected in EUR (1 EUR - $33 \mathrm{UAH}$ ). Thus, the value of the range of losses as a result of emergency situations for 2018 is 13.7...15.69 million EUR, and the actual value is 15.45 million EUR. It should be noted that the larger the sample of statistical data for previous years, the more accurate forecasting can be made. In addition, it is possible to use OTM to make a forecast for a longer period (two, three years). However, this will lead to a significant increase in the relative error.

The main disadvantage of the existing methods and models for forecasting emergencies and damage caused is the focus on forecasting certain types of emergencies, does not allow for a comprehensive forecast of emergencies as a whole.

The advantage of the developed OTM is that it has a combined character. OTM allows to forecast the processes of emergencies in a complex manner, by nature, types, levels, and to assess 
possible losses as their results, both in the state and in its regions. The model for forecasting the number of emergency situations for a certain warning period makes a forecast taking into account the systematic (trend), periodic and random components of this process. Evaluation of these components of the forecasting process allows for a deeper analysis of the causes of their occurrence.

In the results of experimental studies, it was found that OTM makes it possible to forecast emergency situations as a whole, by type and level for a year ahead with an average relative forecast error of no more than $8 \%$. The error in estimating possible losses caused as a result of an accident is no more than $6.2 \%$ (Table 1). This is due to the combination of various methods, in particular the polynomial-regression method with variable order, the weighted least squares method and the probabilistic-statistical method, allowing to compensate for the shortcomings of some at the expense of others.

The developed OTM allows reasonably, taking into account predictive information about the processes of emergencies in the state, regions, to approach the planning and implementation of organizational and technical measures aimed at preventing emergencies and minimizing possible consequences.

Restrictions on the use of OTM may be caused by the insufficient volume or incorrectness of reliable statistical data on emergencies in the state and its regions.

Further development of research in this direction should be focused on studying the influence of various destabilizing factors, both separately and in their totality. As such factors, it is possible to consider the frequency and cyclicality of the processes of emergencies (in particular, their seasonal fluctuations) in the state and its various regions of the country.

Thus, the aforementioned confirms the prospects of applying OTM to solving the problem of forecasting emergencies and the damage caused as their results.

\section{Conclusions}

1. OTP for forecasting emergencies and possible losses caused as their results has been developed. The method is based on a formalized mathematical model, which includes models for forecasting emergencies as a whole, by type, level and possible losses as their results both on a national scale and in each region. OTM combines a variable-order polynomial-regression method, a weighted least squares method, and a probabilistic-statistical method. The use of the method makes it possible to improve the accuracy of forecasting emergency situations and assessing possible losses both in the state as a whole and in its regions. The method implements the principle of a systematic approach to solving the problem of comprehensive forecasting of emergency processes both in the state and its regions. This makes it possible to reasonably approach the planning and implementation of organizational and technical measures to prevent emergencies, taking into account the potential threats to the territories and population of the country's regions.

2. A control algorithm has been developed that implements OTM for forecasting emergency situations and possible losses caused as their results. Its use involves the implementation of a number of interrelated procedures. At the first stage, the collection, processing and analysis of information about emergencies in the state for a certain period of monitoring is carried out. This is the basis for predicting the processes of emergencies in general, in terms of nature, level and types, as well as losses due to them both in the state and its regions. The information obtained is taken into account when forming a decision on the actions of the central control units in order to adequately respond to emergencies and eliminate their consequences. Based on the analysis of the effectiveness of the actions of the response units, the decisions on the elimination of emergencies are adjusted. The algorithm consists of 9 blocks located at 7 hierarchical levels and connected by direct and reverse logical connections.

3. The results of experimental studies have shown that the use of OTM makes it possible to forecast emergencies in general, by type and level, both in the state and in its regions. Moreover, the average relative forecast error does not exceed $8 \%$. The average relative error in forecasting possible incurred losses as a result of an accident is $6.2 \%$. The effectiveness of the use of OTM will depend on the reliability of statistical data on the nature, type, level of emergencies and their regional distribution in the state for a certain period of monitoring. 


\section{References}

[1] Chen, W.-K. (2012). Managing Emergency Response of Air Pollution by the Expert System. Air Pollution - A Comprehensive Perspective. doi: https://doi.org/10.5772/50080

[2] Guskova, N. D., Neretina, E. A. (2013). Threats of natural character, factors affecting sustainable development of territories and their prevention. Zbornik Radova Geografskog Instituta Jovan Cvijic, SANU, 63 (3), 227-237. doi: https://doi.org/ 10.2298/ijgi1303227g

[3] Rybalova, O., Artemiev, S., Sarapina, M., Tsymbal, B., Bakhareva, A., Shestopalov, O., Filenko, O. (2018). Development of methods for estimating the environmental risk of degradation of the surface water state. Eastern-European Journal of Enterprise Technologies, 2 (10 (92)), 4-17. doi: https://doi.org/10.15587/1729-4061.2018.127829

[4] Tiutiunyk, V. V., Ivanets, H. V., Tolkunov, I. A., Stetsyuk, E. I. (2018). System approach for readiness assessment units of civil defense to actions at emergency situations. Scientific Bulletin of National Mining University, 1, 99-105. doi: https://doi.org/ $10.29202 /$ nvngu/2018-1/7

[5] Novoselov, S. V., Panikhidnikov, S. A. (2017). Problems in prediction of number of emergencies by statistical methods. Mining Informational and Analytical Bulletin, 10, 60-71. doi: https://doi.org/10.25018/0236-1493-2017-10-0-60-71

[6] Ivanets, H., Horielyshev, S., Ivanets, M., Baulin, D., Tolkunov, I., Gleizer, N., Nakonechnyi, A. (2018). Development of combined method for predicting the process of the occurrence of emergencies of natural character. Eastern-European Journal of Enterprise Technologies, 5 (10 (95)), 48-55. doi: https://doi.org/10.15587/1729-4061.2018.143045

[7] Deng, S. C., Wu, Q., Shi, B., Chen, X. Q., Chu, X. M. (2014). Prediction of Resource for Responding Waterway Transportation Emergency Based on Case-Based Reasoning. China Safety Science Journal, 24 (3), 79-84.

[8] Vasiliev, M. I., Movchan, I. O., Koval, O. M. (2014). Diminishing of ecological risk via optimization of fire-extinguishing system projects in timber-yards. Scientific Bulletin of National mining university, 5, 106-113. http://www.nvngu.in.ua/ index.php/en/component/jdownloads/finish/49-05/1443-2014-5-vasiliev/0

[9] Sun, B., Ma, W., Zhao, H. (2013). A fuzzy rough set approach to emergency material demand prediction over two universes. Applied Mathematical Modelling, 37 (10-11), 7062-7070. doi: https://doi.org/10.1016/j.apm.2013.02.008

[10] Kryanev, A., Ivanov, V., Romanova, A., Sevastianov, L., Udumyan, D. (2018). Extrapolation of Functions of Many Variables by Means of Metric Analysis. EPJ Web of Conferences, 173, 03014. doi: https://doi.org/10.1051/epjconf/201817303014

[11] Al-Jumeily, D., Ghazali, R., Hussain, A. (2014). Predicting Physical Time Series Using Dynamic Ridge Polynomial Neural Networks. PLoS ONE, 9 (8), e105766. doi: https://doi.org/10.1371/journal.pone.0105766

[12] Evangeliou, N., Balkanski, Y., Cozic, A., Hao, W. M., Mouillot, F., Thonicke, K. et. al. (2015). Fire evolution in the radioactive forests of Ukraine and Belarus: future risks for the population and the environment. Ecological Monographs, 85 (1), 49-72. doi: https://doi.org/10.1890/14-1227.1

[13] Goldammer, J. G., Kashparov, V., Zibtsev, S., Robinson, S. (2014). Best practices and recommendations for wildfire suppression in contaminated areas, with focus on radioactive terrain. OSCE. Available at: http://gfmc.online/globalnetworks/seeurope/ OSCE-GFMC-Report-Fire-Management-Contaminated-Terrain-2014-ENG.pdf

[14] Migalenko, K., Nuianzin, V., Zemlianskyi, A., Dominik, A., Pozdieiev, S. (2018). Development of the technique for restricting the propagation of fire in natural peat ecosystems. Eastern-European Journal of Enterprise Technologies, 1 (10 (91)), 31-37. doi: https://oi.org/10.15587/1729-4061.2018.121727

[15] Ivanets, H., Ivanets, M. (2019). Algorithm increase exactness of prognostication process origin extraordinary situations on basis regressive models. Nauka i tekhnika Povitrianykh Syl Zbroinykh Syl Ukrainy, 1 (34), 117-122. doi: https://doi.org/ 10.30748/nitps.2019.34.16

[16] Zvit pro osnovni rezultaty diyalnosti Derzhavnoi sluzhby Ukrainy z nadzvychainykh sytuatsiy u 2018 rotsi. Available at: https://www.dsns.gov.ua/files/2019/1/18/321/\%D0\%9F\%D1\%83\%D0\%B1\%D0\%BB \%D1\%96\%D1\%87\%D0\%BD\%D0\% B8\%D0\%B9\%20\%D0\%B7\%D0\%B2\%D0\%B8\%D1\%82\%20\%D0\%B7\%D0\%B0\%202018\%20\%D1\%80\%D1\%96\%D0\%BA.pdf

[17] Zvit pro osnovni rezultaty diyalnosti Derzhavnoi sluzhby Ukrainy z nadzvychainykh sytuatsiy u 2017 rotsi. Available at: http://www.dsns.gov.ua/files/2018/1/26/Zvit\%202017(KMY).pdf

Received date 17.02.2021

(C) The Author(s) 2021

Accepted date 05.08.2021

Published date 13.09.2021

This is an open access article under the Creative Commons CC BY license

How to cite: Ivanets, H., Horielyshev, S., Sagradian, M., Ivanets, M., Boikov, I., Baulin, D., Kozlov, Y., Nakonechnyi, A., Safoshkina, L. (2021). Development of organizational and technical methods for predicting emergency situations and possible losses as their results. EUREKA: Physics and Engineering, 5, 121-132. doi: https://doi.org/10.21303/2461-4262.2021.002007 